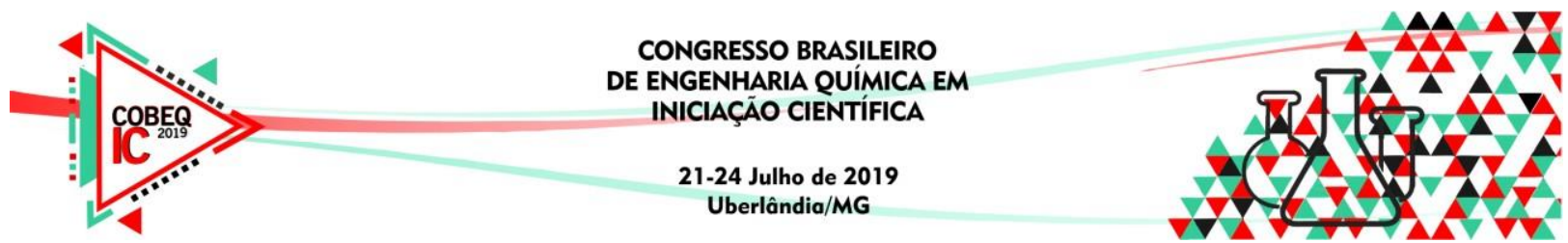

\title{
AVALIAÇÃO DO POTENCIAL DE ADSORÇÃO DE ÍONS METÁLICOS E DO CORANTE DE AZUL DE METILENO EM ARGILA IN NATURA E TRATADA SUPERFICIALMENTE
}

\author{
L. CAMPOS ${ }^{1}$, B. S. LEONE ${ }^{2}$, J. S. BORGES ${ }^{2}$ e M. S. R. GOMES ${ }^{2}$ \\ ${ }^{1}$ Faculdades Integradas de Aracruz-FAACZ, Curso de Engenharia Química \\ ${ }^{2}$ Faculdades Integradas de Aracruz-FAACZ, Departamento de Engenharia Química \\ E-mail para contato: lc.lenicecampos@gmail.com
}

\begin{abstract}
RESUMO - O presente trabalho visa avaliar a argila in natura e após alterações superficiais como adsorvente, quando aplicada no tratamento de efluentes. Para isso, uma amostra de argila coletada no município de Aracruz-ES foi modificada por processos de ativação, funcionalização e tratamento térmico, a fim de melhorar a sua capacidade adsortiva para elementos metálicos e corante de azul de metileno em soluções aquosas. A adsorção dos metais foi avaliada por análise de espectrometria de emissão atômica com plasma acoplado indutivamente (ICP OES) e a adsorção do corante foi verificada por meio de espectrofotômetro UV- Vis. Observaram-se bons resultados de adsorção dos íons metálicos Cromo $\mathrm{Cr}$ (VI) e Chumbo $\mathrm{Pb}(\mathrm{II})$. A argila in natura demonstrou excelente resultado na remoção do corante e as argilas modificadas, em especial a ativada com Cloreto de Bário $\left(\mathrm{BaCl}_{2}\right)$. Os resultados revelaram que, de acordo com a espécie química avaliada, a argila in natura ou modificada apresentou potencial para sua utilização como adsorvente.
\end{abstract}

\section{INTRODUÇÃO}

Uma das grandes preocupações atuais, em relação à água, tem ligação com a sua poluição através de efluentes industriais com concentrações de metais pesados acima do estabelecido pela legislação vigente, a exemplo a contaminação ocorrida após o rompimento das barragens de Fundão, em Mariana e da mina de Córrego do Feijão, em Brumadinho, ambas em Minas Gerais. Esse despejo inadequado da lama de rejeitos de minérios, ocasionou desequilíbrio ecológico e prejuízos socioeconômicos. Industrialmente, alguns processos de produção, como indústrias têxteis, metalúrgicas, plástico PVC, cloro e o processo de curtimento do couro, utilizam metais pesados, corantes e pigmentos que, quando são despejados irregularmente tanto em corpos d'água quanto na rede de esgotos provocam a contaminação (DEL SORDO FILHO, 2015; ALBUQUERQUE, 2019). De acordo com Módenes et al. (2013) é imprescindível a remoção de corantes e pigmentos dos efluentes industriais antes de serem despejados nos corpos hídricos, pois, esses corantes provocam o aumento da temperatura, problemas estéticos, e também impedem a penetração de luz, havendo facilidade de causar distúrbios em corpos receptores.

As argilas apresentam propriedades químicas e estruturais interessantes, que aumentam o seu potencial como adsorvente em tratamento de águas, como: a composição 


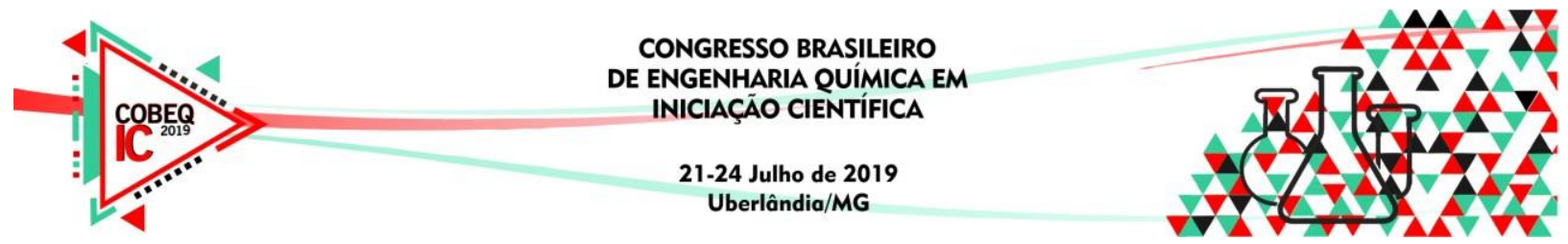

química, sua grande área superficial, tamanho de partículas, porosidade, alta capacidade adsortiva, resistência a grandes variações de $\mathrm{pH}$, estabilidade química e física e capacidade catiônica. Além disso, esse material possui vantagens econômicas e de abundância, pois, o custo desse material comparado com outros adsorventes comumente estudados é normalmente bastante inferior. Essa associação das propriedades químicas e do seu custo, potencializa a utilização argilomineral como adsorvente na área ambiental e na área tecnológica (CANTUARIA, 2014; DEL SORDO FILHO, 2015). Entretanto, com o intuito de melhorar suas propriedades adsortivas, torna-se necessário submetê-las a tratamentos, que promovem a modificação superficial das argilas ("surface treated clays"), como a destruição das lamelas, a eliminação de impurezas e alterações da composição química e estrutural da argila, resultando no aumento da área superficial, porosidade e no número de sítios ácidos, em consequência as argilas tratadas aumentam sua capacidade de adsorver os íons metálicos e corantes (LENARDA, 2007 apud DEL SORDO FILHO, 2015).

As argilas produzidas no Espírito Santo são provenientes de depósitos formados em áreas de inundações de rios, as planícies aluviais, e, secundariamente, de camadas de argilitos e siltitos do Grupo Barreiras. Nos estudos apresentados por Melo et al. (2002) no município de Aracruz, a camada de $14 \mathrm{~m}$ de profundidade é considerada o material de excelência da mina, correspondendo a um siltito argiloso esbranquiçado, bastante homogêneo, contendo a caulinita como principal mineral da fração argila. Sendo o grupo da caulinita, argilominerais constituídos por camadas do tipo 1:1, com uma composição teórica de 46,5\% de $\mathrm{SiO}_{2}, 39,5 \%$ de $\mathrm{Al}_{2} \mathrm{O}_{3}$ e $14,0 \%$ de água, não permitindo a substituição na camada tetraédrica, do $\mathrm{Si}^{4+}$ pelo $\mathrm{Al}^{3+} \mathrm{e}$ nem do $\mathrm{Al}^{3+}$ por outros íons na camada octaédrica ( ARAGÃO et al. 2013).

Diante desse contexto, em função dos impactos ambientais negativos de metais pesados e corantes, a presente pesquisa tem como objetivo avaliar o potencial adsorvente de uma amostra de argila, testada na sua forma in natura e modificada superficialmente, na remoção de íons metálicos e corante Azul de Metileno (AM) em soluções aquosas.

\section{MATERIAIS E MÉTODOS}

\subsection{Coleta e Preparação dos Materiais}

No desenvolvimento desta pesquisa, a argila utilizada como adsorvente, foi cedida pela empresa DLL Extração e Comércio de Argila, localizada no Bairro Vila do Riacho, região litorânea do município de Aracruz. A amostra de argila foi previamente desagregada em almofariz e padronizada em processo de peneiramento em malha de 200 mesh $(0,074 \mathrm{~mm})$. Como adsorvato foram utilizados o corante azul de metileno com soluções aquosas diluídas de $0,1 \mathrm{mg} / \mathrm{L}$ à $10 \mathrm{mg} / \mathrm{L}$ e soluções sintéticas que foram preparadas em laboratório, a partir da diluição de padrões da marca QHEMIS®, com concentração de 1000 ppm dos íons metálicos Alumínio [Al(III)], Cálcio [Ca(II)], Cromo [Cr(VI)], Cobre [Cu(II)], Chumbo [Pb(II)] e Sódio [Na(I)], para obter diferentes concentrações de íons metálicos: 0.2 ppm, 0.5 ppm, 1 ppm, 5 ppm, e $10 \mathrm{ppm}$. Além disso, outro adsorvente utilizado para fins de comparação nos experimentos para o tratamento de água, foi a resina catiônica cedida por uma empresa da região, regenerada com ativação em meio ácido $\mathrm{HCl}$ (4M), do tipo Dowex Monosphere 650C ou Amberjet 1200, que se caracteriza por ser do tipo forte, grupo funcional 


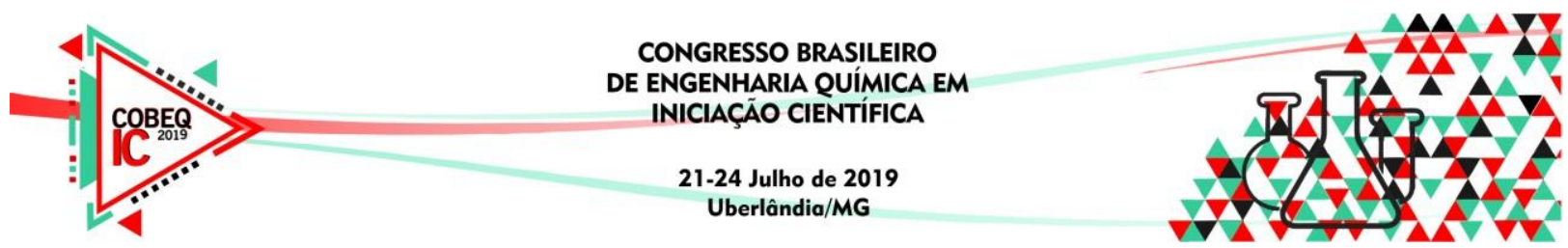

sulfônico, forma iônica $\left(\mathrm{H}^{+}\right)$, resina úmida, volume de $2.700 \mathrm{~L}$, altura da camada $600 \mathrm{~mm}$ e malha $650 \pm 50 \mu \mathrm{m}$.

\subsection{Modificações da Argila}

Tratamento térmico: A argila in natura foi submetida ao processo de calcinação em Forno Mufla marca Quimis, modelo Q-318021, à $500^{\circ} \mathrm{C}$ pelo período de 24 horas (SILVA et al., 2014).

Ativação com Cloreto de Sódio $(\mathrm{NaCl}) 1 \mathrm{~mol} \mathrm{~L}^{-1}$ : A argila in natura, foi suspensa em água destilada e, após esse processo, foi adicionado $\mathrm{NaCl}$, respeitando-se a proporção de $1 \mathrm{~g}$ de material adsorvente para $25 \mathrm{~mL}$ de solução, resultando em uma solução $1 \mathrm{~mol} \mathrm{~L}^{-1}$, mantida sob agitação constante, durante um período de 24 horas, à $25^{\circ} \mathrm{C}$. Ao final do período, aguardou-se 10 minutos, para decantação e retirada do sobrenadante, sendo o processo repetido com água desmineralizada para lavagem por mais 4 vezes. Posteriormente o decantado foi levado à estufa marca Bioespectro, modelo SP- 220 , à $100^{\circ} \mathrm{C}$ por 24 horas para secagem. A argila ativada e seca, foi macerada e colocada em pesa filtro e armazenada em dessecador (RODRIGUES et al., 2004).

Ativação com Cloreto de Bário $\left(\mathrm{BaCl}_{2}\right) 1 \mathrm{~mol} \mathrm{~L}{ }^{-1}$ : Foi realizado baseando-se no estudo de Oliveira (2006) e, de forma análoga ao descrito para a ativação com $\mathrm{NaCl}$.

Funcionalização: A amostra de argila ativada em solução de $\mathrm{NaCl} 1 \mathrm{~mol} \mathrm{~L}^{-1}$ foi funcionalizada com solução de $\mathrm{BaCl}_{2} 1 \mathrm{~mol} \mathrm{~L}^{-1}$, processo que consistiu na submissão da argila tratada à um segundo tratamento, o qual denomina-se funcionalização (LADEIRA, 2016).

\subsection{Análise da Eficiência de Adsorção}

Testes de Adsorção: Para avaliar os efeitos da argila in natura e pós tratada e, uma amostra de resina catiônica, foram realizados ensaios em bateladas, no qual foi calculado a porcentagem de remoção dos íons metálicos. Para esses sistemas, foram realizados os ensaios com as seguintes especificações: $1 \mathrm{~g}$ de adsorvente adicionados a $25 \mathrm{~mL}$ da solução de íons metálicos e mantidas em contato durante 60 minutos, à $25^{\circ} \mathrm{C}$, sob agitação constante, para formação de suspensão homogênea e posteriormente foi filtrado, conforme o método de Aragão et al.(2013). Os filtrados gerados foram analisados utilizando a técnica de espectrometria de emissão atômica com plasma acoplado indutivamente (ICP OES) marca PerkinElmer, modelo Optima 4300 DV, a fim de determinar as concentrações dos íons metálicos após o teste de adsorção. No teste de adsorção com corante azul de metileno utilizou-se $0,4 \mathrm{~g}$ de adsorvente para $50 \mathrm{~mL}$ de solução de corante com concentração de $100 \mathrm{mg} \mathrm{L}^{-1}$ e mantidas em contato durante 30 minutos, sob agitação constante em agitador magnético. Em seguida, após breve repouso, alíquotas dos sobrenadantes foram coletadas e centrifugadas para posterior determinação da concentração do azul de metileno, sendo determinada uma curva da concentração x absorbância com o auxílio de um espectrofotômetro de UV-VIS marca Bioespectro SP, modelo SP 220, comprimento de onda de 665nm, empregando-se uma cubeta de quartzo de caminho óptico de $1,0 \mathrm{~cm}$, conforme o 


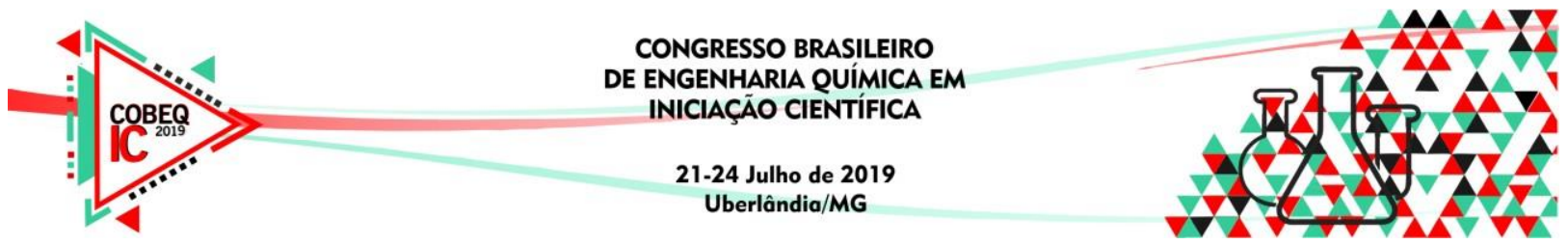

estudo de Freitag (2013). A curva padrão obtida foi de [Concentração de corante] = 10,43 [Absorbância] (com coeficiente de determinação de $\mathrm{R}^{2}=0,9989$ ).

\section{RESULTADOS E DISCUSSÃO}

A argila in natura com coloração esbranquiçada, após tratada superficialmente obteve mudança na textura, pois ficaram mais finas e homogêneas após desagregação e apresentaram mudança na coloração das argilas modificadas, demonstradas na Figura 1.

Figura 1. Amostras de argilas in natura, ativadas com $\mathrm{NaCl}$, termicamente, $\mathrm{BaCl}_{2} \mathrm{e}$ funcionalizada, respectivamente. Fonte: autores, 2018.

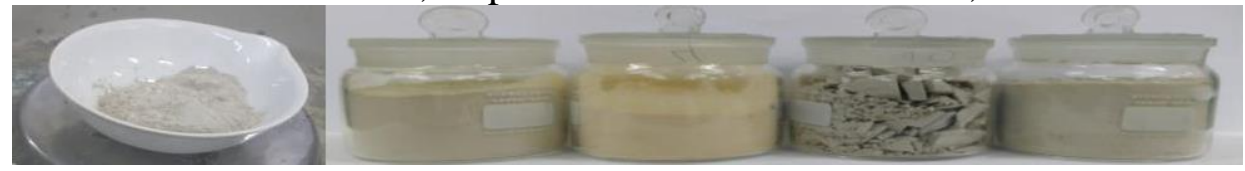

A partir dos dados resultantes das concentrações dos íons metálicos adsorvidos obtidos por (ICP OES), foi possível comparar as concentrações de metais presentes nas amostras de água antes e após o tratamento e calcular o percentual de íons metálicos adsorvidos. De acordo com a Figura 2, as diferentes formas de ativação da argila mostraram-se pouco eficientes como adsorventes para os íons metálicos, em comparação com a resina catiônica. A argila ativada termicamente apresentou resultados menos favoráveis que a argila in natura para a remoção do íon $\mathrm{Cr}(\mathrm{VI})$ de $(0,2 \mathrm{ppm}$ à $10 \mathrm{ppm})$, porém obteve melhores resultados que a agila in natura nas concentrações $(0,2 \mathrm{ppm}$ à $1 \mathrm{ppm})$ para o íon $\mathrm{Pb}(\mathrm{II})$, com valores acima de $70 \%$ de remoção nessas concentrações, e não houve adsorção dos íons $\mathrm{Cr}(\mathrm{VI})$ e $\mathrm{Pb}(\mathrm{II})$ nas concentrações (5ppm e 10ppm), a possível explicação desse comportamento pode estar relacionada ao aumento da concentração desses íons metálicos onde os sítios foram preenchidos impregnando a superfície adsorvedora e impedindo a retenção dos íons, indicando que, em baixas concentrações, a superfície dessa argila tem alta afinidade pela substância adsorvida, sendo que essa afinidade diminui em maiores concentrações. A argila ativada com $\mathrm{NaCl}$ apresentou melhores resulltados de remoção para o íon $\mathrm{Cr}(\mathrm{VI})$ de $(0,2 \mathrm{ppm}$ à $5 \mathrm{ppm})$ e piores resultados com o íon $\mathrm{Pb}$ (II) em comparação com a argila in natura. A argila ativada com $\mathrm{BaCl}_{2}$ demonstrou melhores resultados de remoção para o íon $\mathrm{Cr}(\mathrm{VI})$ em todas as concentrações $(0,2 \mathrm{ppm}$ à $10 \mathrm{ppm})$, porém obteve piores resultados com o íon $\mathrm{Pb}(\mathrm{II})$ na maioria das concentrações em relação a in natura. A argila funcionalizada apresentou baixos resultados de remoção para os íons $\mathrm{Pb}(\mathrm{II})$ e $\mathrm{Cr}(\mathrm{VI})$, sendo os resultados obtidos menos favoráveis que a argila in natura para remoção de íons metálicos.

Com esses valores, nota-se que a argila in natura mostrou-se como bom material adsorvente para os íons estudados, destacando-se em relação às suas formas ativadas quando aplicada na adsorção do íon $\mathrm{Pb}(\mathrm{II})$. Os resultados observados, utilizando-se a argila in natura podem ser explicados pela sua estrutura química, de natureza catiônica, que naturalmente apresenta boa capacidade de adsorção de metais em solução aquosa, por meio da troca de cátions de sua estrutura pelos cátions em solução. As melhores porcentagens de remoção entre as amostras modificadas superficiais, foram observadas nas ativações com $\mathrm{BaCl}_{2} \mathrm{e} \mathrm{NaCl}$, para o íon $\mathrm{Cr}(\mathrm{VI})$ devido à capacidade de troca com os respectivos cátions $\mathrm{Na}(\mathrm{I})$ e $\mathrm{Ba}$ (II). E na argila ativada termicamente para adsorção de íon $\mathrm{Pb}(\mathrm{II})$. 


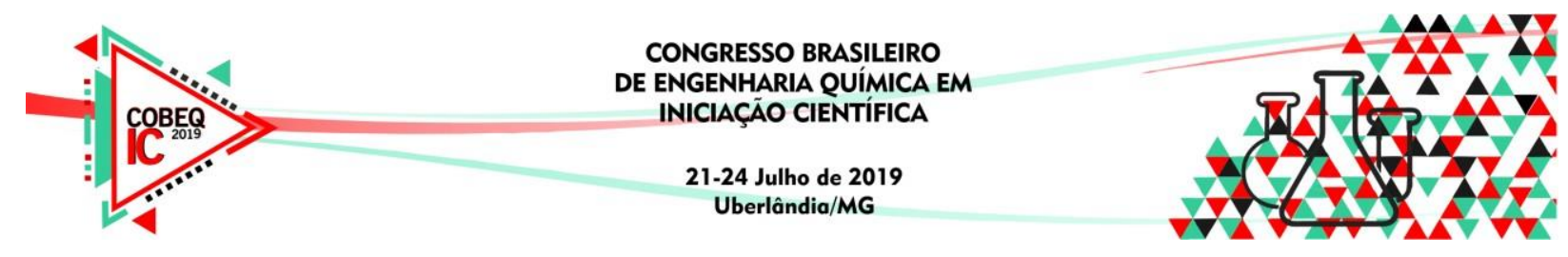

Figura 2: Adsorção dos elementos $\mathrm{Cr}$ e $\mathrm{Pb}$ nas amostras de argilas e resina catiônica. Fonte: autores, 2018.

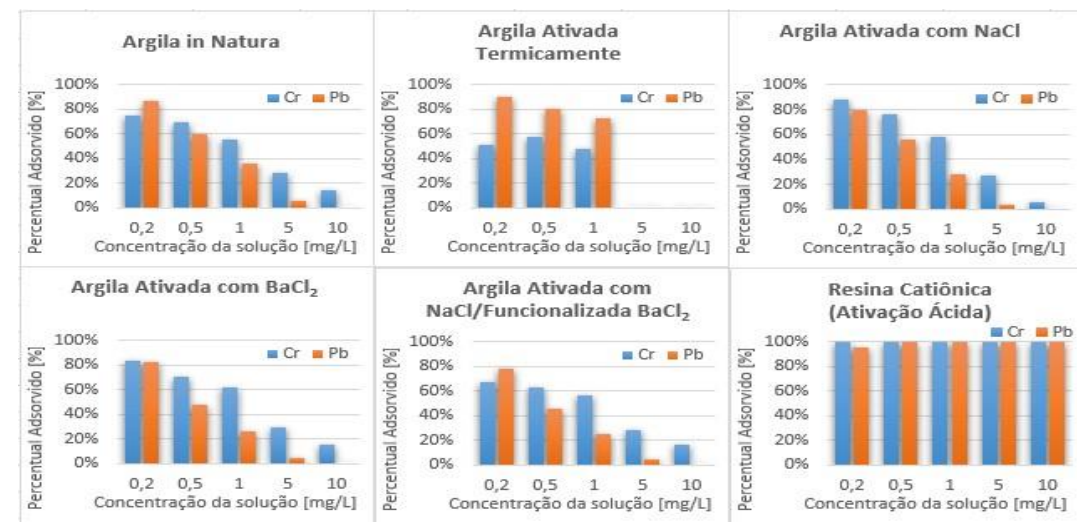

Em contrapartida, os íons $\mathrm{Al}(\mathrm{III})$ e $\mathrm{Ca}(\mathrm{II})$ tiveram percentual adsorvido de $0 \%$ em todos os testes, além de apresentarem suas concentrações aumentadas nas amostras após as modificações superficiais, indicando o processo de dessorção, neste caso, é possível que a argila apresente esses elementos em sua composição os liberando durante o processo. A resina catiônica, utilizada como referência, demonstrou excelentes resultados de adsorção para os íons metálicos, com exceção íon $\mathrm{Na}(\mathrm{I})$, que foi liberado na solução evidenciando o processo de adsorção por troca iônica. Os demais íons analisados, $\mathrm{Cu}(\mathrm{II})$, e $\mathrm{Na}(\mathrm{I})$, não apresentaram comportamento uniforme, tendo sido adsorvidos em determinadas condições de trabalho e na maioria das vezes, adsorvia em quantidades mínimas na menor concentração $(0,1 \mathrm{ppm})$ e nas outras concentrações apresentavam $0 \%$ e liberados em outras.

A partir da curva de calibração do azul de metileno foi possível estimar a concentração final de azul de metileno e o percentual de adsorção proporcionado pelas argilas, disposto na Tabela 1.

Tabela 1: Percentual de adsorção nas amostras tratadas proporcionadas pelas argilas.

\begin{tabular}{c|c}
\hline AMOSTRAS DE ARGILAS & P.A \\
\hline In natura & $98,86 \%$ \\
\hline Tratamento térmico & $96,35 \%$ \\
\hline Ativada $\mathrm{NaCl}$ & $98,73 \%$ \\
\hline Ativada $\mathrm{BaCl}_{2}$ & $99,56 \%$ \\
\hline
\end{tabular}

A argila, que passou por ativação com $\mathrm{BaCl}_{2}$, demonstrou mais eficiência para a remoção do azul de metileno (AM), isso pode ser devido à maior área superficial e maior disponibilidade de sítios ativos para ligação do corante. Porém, a argila ativada com $\mathrm{NaCl}$, também teve bons resultados de remoção, no entanto, foi menor que a argila in natura. A argila ativada termicamente foi a que teve maior redução na eficiência de adsorção, que pode ter sido devido à redução de espécies capazes de interagir com o azul de metileno, diminuindo assim a Capacidade de Troca de Cátions (CTC) com o aumento da temperatura.

\section{CONCLUSÃO}

A partir da observação dos resultados de adsorção obtidos nos testes utilizando as argilas in natura e modificadas do município de Aracruz-ES é possível inferir que, em relação 


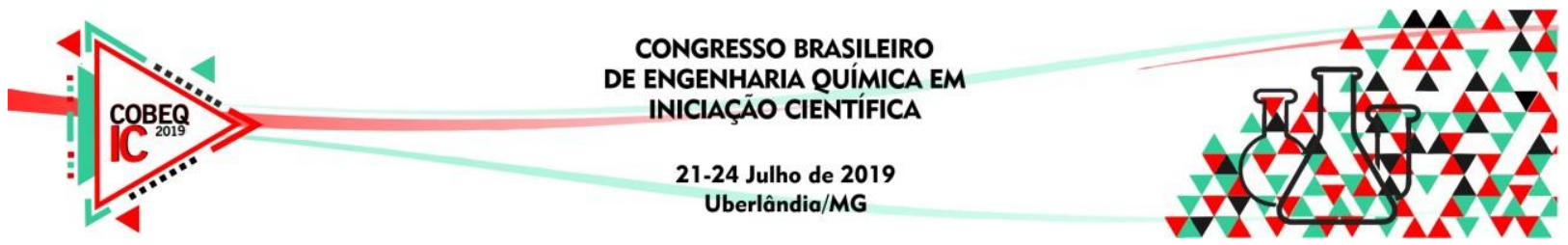

à resina catiônica, apresentaram uma capacidade de adsorção menor, mas o estudo mostrou que a argila pode ser empregada como adsorvente dos íons metálicos $\mathrm{Cr}(\mathrm{VI})$ e $\mathrm{Pb}$ (II), que são metais pesados extremamente tóxicos aos organismos vivos e corante de azul de metileno em soluções aquosas, e que pode substituir outros adsorventes mais caros em função da sua grande disponibilidade, baixo custo e boas propriedades de adsorção. As argilas tratadas superficialmente apresentaram eficiência de adsorção em menores concentrações indicando o potencial para utilização do material como forma de tratamento secundário. E a argila in natura mostrou-se como um bom material adsorvente de maneira geral se destacando para adsorção do íon $\mathrm{Pb}(\mathrm{II})$, mas também adsorveu o íon $\mathrm{Cr}(\mathrm{VI})$.

Além disso, todos os testes na adsorção de azul de metileno demonstraram excelentes resultados de adsorção do corante. Dentre as amostras testadas, a argila ativada com $\mathrm{BaCl}_{2}$ apresentou um maior potencial de adsorção obtendo remoção de $99,56 \%$ do corante pela amostra e a argila in natura também apresentou uma eficiência satisfatória de remoção do corante de $98,86 \%$.

\section{REFERENCIAS}

ARAGÃO, D. M.; ARGUELHO, M. L. P.M.; ALVES, J. P. H.do.; PRADO, C. M. O. Estudo comparativo da adsorção de $\mathrm{Pb}$ (II), $\mathrm{Cd}$ (II) e $\mathrm{Cu}$ (II) em argila natural caulinítica e contendo montmorilonita. Orbital: The Electronic Journal of Chemistry, v. 5, n. 3, p. 157-163, 2013.

CANTUARIA, M. L. Remoção de prata iônica monovalente por adsorção em argila bentonítica. Dissertação (Mestrado) - Em Engenharia Química. Campinas, São Paulo, 2014

DEL SORDO FILHO, G. Estudo da adsorção de íons metálicos em caulinita para água de reuso. 109 p. Dissertação (Mestrado) - Em Ciências na área de tecnologia nuclear. Instituto de pesquisas energéticas e nucleares, São Paulo, 2015.

FREITAG, J. A. Adsorção do corante Azul de Metileno na rama de mandioca (Manihot esculenta crantz). 2013. 41 p. Trabalho de Graduação. (Tecnologia em Processos Químicos). Universidade Tecnológica Federal do Paraná, Toledo, 2013.

LADEIRA, B.C.; SANTANA, L. M. D.; VASSOLER, J.; BOTTAN, T. F. “Avaliação da Eficiência de Adsorção Utilizando a Zeolita Clinoptilolita na Extração de Íons Cromo e Sulfato Através de Adsorção em Leito Fluidizado". Trabalho de Conclusão de Curso. (Engenharia Química). Faculdades Integradas de Aracruz, 2016.

MELO, V. F.; NOVAIS, R. F.; SCHAEFER, C. E. G. R.; FONTES, M. P. F.; SINGH, B. Mineralogia das Frações Areia, Silte e Argila de Sedimentos do Grupo Barreiras no Município de Aracruz, Estado do Espírito Santo. Revista Brasileira de Ciência do Solo, vol. 26, núm. 1, pp. 29-41, 2002.

MÓDENES, A. N., Ross, A. A., Souza, B. V., Dotto, J., Geraldi, C. Q. Espinoza-Quiñones, F. R., \& Kroumov, A. D. 2013. Biosorption of BF-4B reactive red dye by using leaves of macrophytes Eichhornia crassipes. Int. J. Bioautomation, 17(1), 33-44, 2013.

OLIVEIRA, C. R. Adsorção-remoção de íons sulfato e isopropilxantato em zeólita natural funcionalizada. Dissertação - UFRGS. Porto Alegre, 2006.

RODRIGUES, M. G. F.; SILVA, M. L. P.; da SILVA, M. G. C. Caracterização da argila bentonítica para utilização na remoção de chumbo de efluentes sintéticos. Cerâmica, v. 50, p. 190-196, 2004.

SILVA, M. P.; Santos, M. S. F.; Xavier, K. C. M.; Carvalho, M. W. N. C.; Osajima, J. A.; Silva Filho, E. C. Paligorsquita ativada termicamente visando a adsorção de $P b^{2+} 8$ p. $21^{\circ}$ CBECIMAT - Realizado 09 a 13 de Novembro de 2014, Cuiabá, Mato Grosso, 2014.

ALBUQUERQUE, C. Tragédia de Brumadinho: por que a história se repete em Minas Gerais? Revista Galileu. Disponível em: <https://revistagalileu.globo.com/Ciencia/Meio-Ambiente/noticia/2019/01/tragedia-debrumadinho-por-que-historia-se-repete-em-minas-gerais.html >.2019. Acesso em 16 de março de 2019. 